\title{
Introduction: Does Information Matter?
}

Paul, Davies; Gregersen, Niels Henrik

Published in:

Information and the Nature of Reality: From Physics to Metaphysics

Publication date:

2010

Document version

Også kaldet Forlagets PDF

Citation for published version (APA):

Paul, D., \& Gregersen, N. H. (2010). Introduction: Does Information Matter? I D. Paul, \& G. Niels Henrik (red.), Information and the Nature of Reality: From Physics to Metaphysics (s. 1-9). Cambridge University Press. 


\title{
Information and the Nature of Reality
}

From Physics to Metaphysics

\author{
Edited by \\ PAUL DAVIES \\ Arizona State University \\ NIELS HENRIK GREGERSEN \\ Copenhagen University
}

(†)

圈 CAMBRIDGE

UNIVERSITY PRESS 
CAMBRIDGE UNIVERSITY PRESS

Cambridge, New York, Melbourne, Madrid, Cape Town,

Singapore, Sāo Paulo, Delhi, Dubai, Tokyo, Mexico City

Cambridge University Press

The Edinburgh Building, Cambridge CB2 8RU, UK

Published in the United States of America by

Cambridge University Press, New York

www.cambridge.org

Information on this title: www.cambridge.org/9780521762250

(C) P. Davies and N. Gregersen 2010

This publication is in copyright. Subject to statutory exception and to the provisions of relevant collective licensing agreements, no reproduction of any part may take place without the written permission of Cambridge University Press.

First published 2010

Printed in the United Kingdom at the University Press, Cambridge

A catalogue record for this publicution is available from the British Library

Library of Congress Cataloguing in Publication data

ISBN 978-0-521-76225-0 Hardback

Cambridge University Press has no responsibility for the persistence or accuracy of URLs for external or third party internet websites referred to in this publication, and does not guarantee that any content on such websites is, or will remain, accurate or appropriate. 


\section{Contents}

About the authors page ix

Acknowledgments $\mathrm{xV}$

1 Introduction: does information matter? 1

PAUL DAVIES AND NIELS HENRIK GREGERSEN

Part I History 11

2 From matter to materialism ... and (almost) back 13

ERNAN MCMULLIN

3 Unsolved dilemmas: the concept of matter in the history of philosophy and in contemporary physics

PHILIP CLAYTON

4 Universe from bit $\quad 65$

PAUL DAVIES

5 The computational universe $\quad 92$

SETH LLOYD

6 Minds and values in the quantum universe 104

HENRY STAPP

$\begin{array}{ll}\text { Part III Biology } & 121\end{array}$

7 The concept of information in biology 123

IOHN MAYNARD SMITH 
viii CONTENTS

8 What is missing from theories of information?

TERRENCE W. DEACON

9 Information and communication in living matter

BERND-OLAF KÜPPERS

YESPER HOFFMEYER

11 Care on Earth: generating informed concern

HOLMES ROLSTON, III

Part IV Philosophy and Theology

12 The sciences of complexity: a new theological resource?

ARTHUR PEACOCKE

13 God as the ultimate informational principle KEITH WARD

IOHN F. HAUGHT

15 God, matter, and information: towards a Stoicizing Logos Christology

NIELS HENRIK GREGERSEN

16 What is the 'spiritual body'? On what may be regarded as 'ultimate' in the interrelation between God, matter, and information

MICHAEL WELKER

Index 


\title{
I Introduction: does information matter?
}

\author{
Paul Davies and Niels Henrik Gregersen
}

It is no longer a secret that inherited notions of matter and the material world have not been able to sustain the revolutionary developments of twentieth-century physics and biology. For centuries Isaac Newton's idea of matter as consisting of 'solid, massy, hard, impenetrable, and movable particles' reigned in combination with a strong view of laws of nature that were supposed to prescribe exactly, on the basis of the present physical situation, what was going to happen in the future. This complex of scientific materialism and mechanism was easily amalgamated with common-sense assumptions of solid matter as the bedrock of all reality. In the world view of classical materialism (having its heyday between 1650 and 1900), it was claimed that all physical systems are nothing but collections of inert particles slavishly complying with deterministic laws. Complex systems such as living organisms, societies, and human persons, could, according to this reductionist world view, ultimately be explained in terms of material components and their chemical interactions.

However, the emergence of thermodynamics around 1850 already began to cast doubt on the universal scope of determinism. Without initially questioning the inherited concepts of corpuscular matter and mechanism, it turned out that the physics of fluids and gases in thermodynamically open systems can be tackled, from a practical point of view, only by using statistical methods; the aim of tracking individual molecules had to be abandoned. In what has been aptly been called The Probabilistic Revolution (Krüger, Daston, and Heidelberger, 1990|, determinism became a matter of metaphysical

Information and the Nature of Reality: From Physics to Metaphysics, eds. Paul Davies and Niels Henrik Gregersen. Published by Cambridge University Press (C) P. Davies and N. Gregersen 2010. 
belief rather than a scientifically substantiated position. By the 1870 s a great physicist such as James Clerk Maxwell was already questioning the assumption of determinism by pointing to highly unstable systems in which infinitesimal variations in initial conditions lead to large and irreversible effects (later to become a central feature of chaos theory). It was not until the twentieth century, however, that the importance of non-equilibrium dissipative structures in thermodynamics led scientists such as Ilya Prigogine (1996) to formulate a more general attack on the assumptions of reversibility and scientific determinism.

What happened, then, to the notion of matter and the material? In a first phase the term 'matter' gradually lost its use in science to be replaced by more robust and measurable concepts of mass (inertial, gravitational, etc). The story of the transformations of the idea of matter into something highly elusive yet still fundamental is told in detail by Ernan McMullin and Philip Clayton in Chapters 2 and 3 of this volume. Here it suffices to point to three new developments of twentieth-century physics in particular that forced the downfall of the inherited Matter Myth, and led to new explorations of the seminal role of information in physical reality.

The first blow came from Einstein's theories of special relativity (1905) and general relativity (1915). By stating the principle of an equivalence of mass and energy, the field character of matter came into focus, and philosophers of science began to discuss to what extent relativity theory implied a 'de-materialization' of the concept of matter. However, as McMullin points out, even though particles and their interactions began to be seen as only partial manifestations of underlying fields of mass-and-energy, relativity theory still gave room for some notion of spatio-temporal entities through the concept of 'rest mass'.

The second blow to classical materialism and mechanism came with quantum theory, which describes a fundamental level of reality, and therefore should be accorded primary status when discussing the current scientific and philosophical nature of matter. 
In Chapters 4, 5, and 6 Paul Davies, Seth Lloyd, and Henry Pierce Stapp challenge some widely held assumptions about physical reality. Davies asks what happens if we do not assume that the mathematical relations of the so-called laws of nature are the most basic level of description, but rather if information is regarded as the foundation on which physical reality is constructed. Davies suggests that instead of taking mathematics to be primary, followed by physics and then information, the picture should be inverted in our explanatory scheme, so that we find the conceptual hierarchy: information $\rightarrow$ laws of physics $\rightarrow$ matter. Lloyd's view of the computational nature of the universe develops this understanding by treating quantum events as 'quantum bits', or qubits, whereby the universe 'registers itself'. Lloyd approaches this subject from the viewpoint of quantum information science, which sets as a major goal the construction of a quantum computer - a device that can process information at the quantum level, thereby achieving a spectacular increase in computational power. The secret of a quantum computer lies with the exploitation of genuine quantum phenomena that have no analogues in classical physics, such as superposition, interference, and entanglement. Quantum computation is an intensely practical programme of research, but Lloyd uses the concept of quantum information science as the basis for an entire world view, declaring that the universe as a whole is a gigantic quantum computer. In other words, nature processes quantum information whenever a physical system evolves.

Lloyd's proposal forms a natural extension of a long tradition of using the pinnacle of technology as a metaphor for the universe. In ancient Greece, surveying equipment and musical instruments were the technical wonders of the age, and the Greeks regarded the cosmos as a manifestation of geometric relationships and musical harmony. In the seventeenth century, clockwork was the most impressive technology, and Newton described a deterministic clockwork universe, with time as an infinitely precise parameter that gauged all cosmic change. In the nineteenth century the steam engine replaced 
clockwork as the technological icon of the age and, sure enough, Clausius, von Helmholtz, Boltzmann, and Maxwell described the universe as a gigantic entropy-generating heat engine, sliding inexorably to a cosmic heat death. Today, the quantum computer serves the corresponding role. Each metaphor has brought its own valuable insights; those deriving from the quantum computation model of the universe are only just being explored.

In the absence of a functional quantum computer, the most powerful information-processing system known is the human brain (that may change soon, as even classical computers are set to overtake the brain in terms of raw bit flips). The relationship between mind and brain is the oldest problem of philosophy, and is mirrored in the context of this volume by the information-matter dichotomy. Crucially, the brain does more than flip bits. Mental information includes the key quality of semantics; that is, human beings derive understanding of their world from sense data, and can communicate meaning to each other. The question here is what can, and what cannot, be explained merely by digital information, which is formulated in terms of bits without regard to meaning. When the foundation for information theory was laid down by Shannon, he purposely left out of the account any reference to what the information means, and dwelt solely on the transmission aspects. His theory cannot, on its own, explain the semantics and communication of higher-order entities. At most, one could say, as Deacon suggests in Chapter 8, that Shannon focused on the syntactic features of an information potential.

The foregoing properties of the mental realm are closely related to the issue of consciousness. How the brain generates conscious awareness remains a stubborn mystery, but there is a wellestablished school of thought that maintains it has something to do with quantum mechanics. Certainly the role of the observer in quantum mechanics is quite unlike that in classical mechanics. Moreover, if quantum mechanics really does provide the most fundamental description of nature, then at some level it must incorporate 
an account of consciousness and other key mental properties (for example, the emergence of semantics, the impression of free willl. For many years, Henry Stapp has championed the case for understanding the mind and its observer status in a quantum context, and in Chapter 6 he sets out a well-argued case both for taking consciousness seriously /that is, not defining it away as an epiphenomenon) and for accommodating it within a quantum description of nature.

The third challenge to the inherited assumptions of matter and the material comes from evolutionary biology and the new information sciences, which have made revolutionary discoveries since the $1940 \mathrm{~s}$ and 1950s. Placed at the interface of the physical and cultural sciences, biology plays a pivotal role in our understanding of the role of information in nature. In Chapter 7 John Maynard Smith argues that the biological sciences must be seen as informational in nature, since the sequence structure of DNA is causally related, in a systematic way, to the production of proteins. In the nineteenth century, living organisms were viewed as some sort of magic matter infused with a vital force. Today, the cell is treated as a supercomputer an information-processing and -replicating system of extraordinary fidelity. The informational aspects of modern molecular biology are conspicuous in the way that gene sequencing and gene pathways now form the foundation for understanding not only evolutionary biology, but also cell biology and medicine. In Chapters 8 and 9 Terrence Deacon and Bernd-Olaf Küppers offer two distinct naturalistic views about how the crucial semantic levels of information might emerge via thermodynamical (Boltzmann) and evolutionary (Darwinian) processes. Both accounts argue that biological information is not only instructional but also has to do with 'valued' or 'significant' information, which puts the receiver in the centre of interest. Significant information, however, is always a subset of a wider set of informational states, which may be described as the underlying information potential'. With this background, Deacon presents a naturalistic theory of the emergence of contextual information; that is, the 
capacity for reference and meaning, which he describes in terms of the notion of 'absent realities'. This he accomplishes by combining the Shannon-Boltzmann view that information is always relative to a statistical information potential, with the Darwinian emphasis on what actually works for an organism in its pragmatic setting. In Chapter 10 Jesper Hoffmeyer then presents a biosemiotic proposal, which questions the overarching role of genetics, and rather opts for the importance of a cell-centred view. Finally, in Chapter 11, Holmes Rolston offers a natural history of the emergence of an informed concern for others. Evolution is a notoriously 'selfish' process, but eventually it generates systems that display altruism and exhibit concern for other beings. With the increase of sense perception and the top-down capacities of mammalian brains, an ethical dimension of nature arrives on the evolutionary scene. A cell-centred view is not necessarily a self-centred view.

It would be wrong to claim that the science-based chapters collectively amount to an accepted and coherent new view on the fundamental role of information in the material world. Many scientists continue to regard matter and energy as the primary currency of nature, and information to be a secondary, or derived concept. And it is true that we lack the informational equivalent of Newton's laws of mechanics. Indeed, we do not even possess a simple and unequivocal physical measure for information, as we have for mass and energy in terms of the units of gram and joule. Critics may therefore suspect that 'information' amounts to little more than a fashionable metaphor that we use as a shorthand for various purposes, as when we speak about information technologies, or about anything that is 'structured', or some way or another 'makes sense' to us.

The incomplete nature of information theory is exemplified by the several distinct meanings of the term 'information' used by the contributors in this volume. Quantum events as informational qubits (Lloyd), for example, have a very different character from Shannon-type digital information, or as mere patterns (Aristotelian information), and none of the foregoing can much illuminate the 
emergent concept of meaningful information (semantic information). In spite of the tentative nature of the subject, however, two reasons can be offered for giving information a central role in a scientifically informed ontology. The main point is that information makes a causal difference to our world - something that is immediately obvious when we think of human agency. But even at the quantum level, information matters. A wave function is an encapsulation of all that is known about a quantum system. When an observation is made, and that encapsulated knowledge changes, so does the wave function, and hence the subsequent quantum evolution of the system. Moreover, informational structures also play an undeniable causal role in material constellations, as we see in, for example, the physical phenomenon of resonance, or in biological systems such as DNA sequences. What is a gene, after all, but a set of coded instructions for a molecular system to carry out a task? No evolutionary theory can have explanatory function without attending to the instructional role of DNA sequences, and other topological structures. But neither can a bridge or skyscraper be constructed successfully without paying due attention to the phenomenon of resonance, and so it seems that just as informational events are quintessential at the lowest level of quantum reality, so are informational structures quintessential as driving forces for the historical unfolding of physical reality.

The philosophical perspectives of a material world based on an irreducible triad of mass, energy, and information are discussed in the contributions in the section on philosophy and theology. In Chapter 12 the late biologist and theologian Arthur Peacocke (to whom this book is dedicated) presents his integrative view about how an emergentist monism, informed by the sciences of complexity, must be sensitive to the uniformity of the material world as well as to the distinctive levels that come up at later stages of evolution. Peacocke's theological synthesis thus combines naturalism and emergentism with a panentheistic concept of God; that is, God permeates the world of nature from within, although God is more 
8 PAUL DAVIES AND NIELS HENRIK GREGERSEN

than the world of nature in its entirety. Peacocke's religious vision is thus developed within the horizon of what he calls EPN (emergentist/monist-panentheistic-naturalist). In Chapters 13 and 14 the philosophical theologians Keith Ward and John F. Haught explore novel ways for understanding God as the source of information for a self-developing world. Ward argues for what he calls a supreme informational principle of the universe, without which the combination of the lawfulness of the world and its inherent value would be inexplicable. Such informational code for construction of an actual universe logically precedes material configurations by containing the set of all mathematically possible states, plus a selective principle of evaluation that gives preference to the actual world that we inhabit. Ward suggests that this primary ontological reality may be identified with God, especially if the given laws of nature can be seen as providing space for qualities such as goodness and intrinsic value. Haught argues that information must walk the razor's edge between redundancy (too much order) and noise (too much contingency). It is this felicitous blend of order and novelty that transforms the universe from a mere physical system into a narrative of information processing. While reminding us that all 'God language' must be regarded as analogical, he argues that the concept of God as an informational principle at work in the entire cosmic process is far richer than the idea of a designer God at the edge of the universe. While emphasizing the logical space of all nature (Ward) and the evolutionary unfolding thereof (Haught), both draw on contemporary scientific accounts of nature that accord with, or even suggest, a divine reality with world-transforming capacities. A science-based naturalism may thus still allow a distinction between the world of nature (with a small ' $w$ ') and the World in extenso (with a capital ' $W$ 'l. Finally, in Chapters 15 and 16, Niels Henrik Gregersen and Michael Welker argue that the new scientific perspectives of matter and information summarized in this volume give fresh impetus to a reinterpretation of important strands of the Biblical traditions. Gregersen shows how the New Testament concept of a divine Logos 
becoming flesh' (John 1:14) has structural similarities to the ancient Stoic notion of Logos as a fundamental organizing principle of the universe, and should not prematurely be interpreted in a Platonic vein. The Johannine vision of divine Logos being coextensive with the world of matter may be sustained and further elucidated in the context of present-day concepts of matter and information, where the co-presence of order and difference is also emphasized. A typology of four types of information is presented, reaching from quantum information to meaning information. In the final essay, Welker suggests that interdisciplinary discussions (between science, philosophy, and theology/ should be able to move between more general metaphysical proposals and the more specific semantic universes, which often are more attentive to the particulars. One example is Paul's distinction between the perishable 'flesh' and the possibility of specific 'bodies' being filled with divine energy. Such distinctions may also be able to catch the social dimensions of material coexistence, which are left out of account in more generalized forms of metaphysics. According to Paul, the divine Spirit may saturate the spiritual bodies of human beings and bring them into communication, when transformed in God's new creation.

Our hope is that the selection of essays presented in this volume will open a new chapter in the dialogue between the sciences, philosophy, and theology.

\section{REFERENCES}

Krüger, L., Daston, J., and Heidelberger, M., eds (1990). The Probabilistic Revolution, Cambridge, MA: MIT Press.

Prigogine, I. (1996). The End of Certainty. Time, Chaos, and the New Laws of Nature. New York: The Free Press. 
Information and the Nature of Reality From Physics to Metaphysics

Many scientists regard mass and energy as the primary currency of nature. In recent years, however, the concept of information has gained importance.

In this book, eminent scientists, philosophers, and theologians chart various aspects of information, from quantum information to biological and digital information, in order to understand how nature works. Beginning with a historical treatment of the topic, the book also examines physical and biological approaches to information, and the philosophical, theological, and ethical implications. 
